\title{
REVOLUÇÃO, VOLTAS E REVESES* Temporalidade e poder em Cuba
}

\author{
Joáo Felipe Gonçalves \\ Universidade de São Paulo (USP), São Paulo - SP, Brasil. E-mail: joaofg@usp.br
}

DOI: http//dx.doi.org/10.17666/329305/2017

Em minha primeira visita de campo a Havana, em 2000, eu disse a um amigo arquiteto - muito crítico ao governo de Cuba - que eu tinha interesse em estudar o nacionalismo cubano "no período após a Revolução” - expressão que eu, ingenuamente, supunha então que simplesmente designava o período após 1959. Mas minha frase não fez sentido para meu interlocutor. Ele me olhou surpreso e me perguntou se eu queria escrever sobre o futuro, pois, ele me esclareceu, "a Revolução ainda está no poder”. Dias depois, já corrigindo minha linguagem,

* Este artigo é um dos resultados do pós-doutorado realizado no Departamento de Antropologia da Universidade de São Paulo, financiado por uma bolsa da Fundaçáo de Apoio à Pesquisa do Estado de São Paulo (Fapesp), processo 2013/23833-8. Agradeço à Fapesp o generoso apoio para a realização deste artigo.

Artigo recebido em 22/05/2015

Aprovado em 04/07/2016 mencionei à diretora de um museu - uma entusiasta defensora do governo da ilha - que eu gostaria de pesquisar o nacionalismo cubano "durante a Revolução". Depois de um suspiro de claro descontentamento, ela me perguntou se eu queria realmente estudar todo o período revolucionário. Quando disse que sim, ela me explicou didaticamente que a "Revolução" havia começado no século XIX, e que vivia hoje apenas "sua mais recente etapa, depois de haver triunfado em 1959". ${ }^{1}$

Nesses momentos de estranhamento etnográfico, um desentendimento inicial me apontava para os vários significados que o termo "Revolução" pode ter em Cuba atualmente. Como essas anedotas etnográficas indicam, tal termo pode designar, entre outras coisas, tanto o atual regime socialista como o processo histórico de libertação nacional iniciado com a eclosão da primeira guerra de independência, em 1868. O termo "Revolução" - ubíquo e altamente valorizado na Cuba contemporânea - estrutura 
diferentes narrativas históricas reproduzidas aí, especialmente aquelas promovidas pelo Estado. Se cidadãos comuns adotam, adaptam e criticam tais narrativas oficiais em maior ou menor grau, eles quase nunca questionam a polissemia ou o valor nacionalista do significante "Revolução". Mesmo os cubanos mais críticos ao governo e a seu discurso veem esse termo como a base fundamental do nacionalismo cubano e o usam corrente e irrefletidamente para se referir ao governo.

Este artigo examina a polissemia e o valor do termo "Revolução" em Cuba, desenvolvendo dois argumentos inter-relacionados. O primeiro, concernente aos efeitos políticos desses fenômenos, afirma que o uso dessa palavra tem contribuído por quase seis décadas para a conformidade política e para a manutençáo do socialismo no país, em grande medida porque ela designa tanto o regime atual - cuja validade é altamente questionada em Cuba hoje em dia - quanto as lutas anticoloniais do século XIX - cujo valor simbólico e político é muito raramente contestado. Como o Estado conseguiu associar-se ao significado mais literal de um significante inextricavelmente ligado ao nacionalismo cubano, criticar o governo publicamente significa criticar um dos alicerces desse nacionalismo e a própria ideia de soberania nacional.

$\mathrm{O}$ segundo argumento que defendo aqui, de cunho mais teórico, questiona a ideia - primeiramente postulada por Benedict Anderson (1991) e predominante nos estudos atuais do nacionalismo de que o nacionalismo pressupóe uma concepção de "tempo homogêneo e vazio". Este artigo busca mostrar que a temporalidade nacionalista que o termo "Revolução" implica e ajuda a produzir em Cuba é altamente diferenciada, sobredeterminada simbolicamente e baseada em uma relação íntima entre passado e presente. Essa historicidade é, portanto, fundamentalmente diferente daquela que Anderson associa ao nacionalismo, e mesmo oposta a ela. Assim, eu uso o caso cubano para sugerir que a temporalidade subjacente ao nacionalismo se aproxima antes daquilo que Walter Benjamin (2007) chamou de "tempo messiânico".

Para fundamentar esses dois pontos empiricamente, começo com um curto esboço histórico do uso político do termo "Revolução" em Cuba. Em seguida, analiso a importância de narrativas sobre o passado - especialmente sobre o século XIX e a década de 1950 - para o imaginário oficial cubano sobre a "Revolução", mostrando como isso tem gerado uma profusão de aniversários e comemoraçóes que criam uma ligação estreita entre passado e presente. Discuto em seguida como o governo conseguiu dar legitimidade à sua autodescrição como "Revolução" através de uma ênfase em seus reveses e fracassos, que transmite a mensagem de que a "Revoluçáo" ainda existe precisamente porque sua vitória não foi alcançada. Sugiro, por fim, que essa mensagem é aceita pelo público graças, em grande parte, a uma temporalidade cotidiana de frustrações, lutas e fracassos que refletem, na própria experiência diária dos cidadãos comuns, as representaçôes oficiais sobre as dificuldades encontradas pela "Revolução". Ao longo dessas discussôes empíricas explicito as consequências teóricas de minhas conclusóes, buscando contribuir para uma compreensão geral da produção da história e do nacionalismo, para além do caso cubano.

\section{História e poder}

O valor nacionalista da ideia de "Revolução" tem uma longa história em Cuba. Esse valor surgiu e se consolidou em meados do século XIX, quando passou a denotar o emergente movimento armado pela independência do país em relação à Espanha. Tanto a frustrada Guerra dos Dez Anos, entre 1868 e 1878, como a última guerra de independência, entre 1895 e 1898, eram chamadas de "Revolução" por seus participantes e defensores. Já na década de 1860 o termo tornara-se uma palavra-chave do nacionalismo cubano e ganhara um tom essencialista que lhe atribuía subjetividade e agência. Como hoje, a "Revolução" era, já naquela época, discursivamente fetichizada como um ser que agia, pensava, exigia sacrifícios, ganhava algumas batalhas, perdia outras, prometia a redenção nacional etc. (Ferrer, 1999; Helg, 1995; Pérez, 1983, 2006; Thomas, 1998). Depois da independência formal de Cuba, em 1902, a celebração mítica do termo exacerbou-se ainda mais, e as lutas armadas contra os ditadores Gerardo Machado, na década de 1930, 
e Fulgencio Batista, na década de 1950, eram chamadas de "revoluçóes" por todos que as apoiavam ou seja, pela grande maioria da população (Barcia, 2005; Iglesias, 2003; Pérez, 2006; Zanetti, 2006). ${ }^{2}$

Dessa forma, quando o heterogêneo movimento armado liderado por Fidel Castro tomou o poder em 1959, cercado por uma generalizada aprovação popular, havia uma quase unânime euforia em torno do entâo chamado "governo revolucionário" e do termo "Revolução". Durante dois anos, enquanto o novo regime contemplava diversas opções políticas e negava-se a admitir-se como socialista, cubanos das mais distintas convicçóes debatiam o significado concreto do termo "Revolução", alimentando ainda mais seu valor fetichizado. Quando Fidel Castro declarou "o caráter socialista da Revoluçãa”, em abril de 1961, a associação entre "Revolução" e socialismo deixou de ser publicamente questionável em Cuba (Gonçalves, 2013; Guerra, 2012). Por algum tempo os críticos do regime - especialmente em Miami, que se convertia na capital do exílio - se declaravam os verdadeiros "revolucionários" e acusavam o governo de ter "traído a Revoluçáo". Isso é indicado pelos nomes de alguns dos mais importantes entre os inúmeros grupos cubanos de oposição que proliferaram segmentariamente em Miami na década de 1960: Movimiento de Recuperación Revolucionaria, Movimiento de Rescate Revolucionario, Consejo Revolucionario Cubano e Movimiento Revolucionario del Pueblo (García, 1996).

Em menos de uma década, contudo, o novo regime conseguiu ligar-se indissociavelmente ao termo "Revolução", que passou a indicar, no uso cotidiano - e mesmo no exílio -, o próprio governo. Esse sentido atingiu aquilo que Jean e John Comaroff (1991), inspirados por Antonio Gramsci e Stuart Hall, definem como hegemonia: um caráter tácito, irrefletido, inquestionável. Dessa forma, ao contrário de outros casos históricos (como a as Revoluçóes Francesa, Russa etc.) os cubanos da ilha e da diáspora passaram a usar a palavra "Revolução" para designar não mais uma reviravolta política ou transformaçóes sociais profundas, mas o regime estabelecido por tal reviravolta e que gerou tais transformaçóes. Ainda hoje, décadas depois de tais eventos, faz sentido para os cubanos dizer que uma pessoa é contra ou a favor da "Revolução", que apoia ou critica a "Revoluçáo", é grata ou ingrata para com a "Revolução", e que a "Revolução" toma decisóes, age de certas formas, fornece bens e serviços, espera lealdade e gratidão etc. - ou, como disse meu amigo, que a "Revolução" ainda está no poder!

Esse curto esboço histórico é importante para entender as origens da polissemia e do valor nacionalista do termo "Revolução" em Cuba. Mas ele também deixa claro que este artigo não discute a revolução como um processo histórico socioeconômico, mas como aquilo que alguns analistas gostam de chamar "categoria nativa". Parafraseando a feliz expressão de Manuela Carneiro da Cunha (2009), meu interesse é examinar a "Revolução" com aspas e, neste caso, com $\mathrm{R}$ maiúsculo - e não a revolução sem aspas, com $r$ minúsculo. Ou, para usar a linguagem de Pierre Bourdieu (1991), trato aqui da "Revolução" como categoria da prática, e não como categoria analítica. Isso significa que este artigo se insere, menos que em uma antropologia histórica, em uma antropologia da história, no sentido de uma antropologia das representaçōes históricas. ${ }^{3}$

Obviamente, essa antropologia da história pode - e deve - ser também uma antropologia histórica, mas meu interesse aqui é sobretudo na "Revolução" como representação e não como processo histórico. Estou aqui seguindo a diferenciação que Michel-Rolph Trouillot (1995, p. 29) estabelece entre "história 1" (processo) e "história 2" (narrativa). $\mathrm{O}$ autor salienta a ambiguidade fundamental da categoria "história" apontando que há "uma distinção irredutível e uma interseção igualmente irredutível entre o que aconteceu e o que se diz que aconteceu” (Idem, p. 3). Trouillot argumenta que há uma interface, uma sobreposiçáo, entre essas duas noções de história, mas que elas nunca se confundem totalmente - o que o leva a criticar tanto pensadores positivistas quanto construcionistas. Se, como os construcionistas radicais, postulássemos que história é apenas representação, não poderíamos estudar uma das principais maneiras pelas quais o poder produz história - o silenciamento de agentes, eventos e processos.

Este artigo também segue o ponto central de Trouillot de que "o poder é constitutivo da história” e examina uma das formas pelas quais, a seu 
dizer, "o poder em si funciona junto com a história" (Idem, p. 28). Ao mostrar que a polissemia e o valor do termo "Revolução" em Cuba se mantêm em grande parte devido ao discurso e a políticas do governo, e que tal polissemia e valor contribuem para a manutenção desse mesmo governo, investigo aqui uma maneira pela qual representaçóes históricas e poder político se reforçam mutuamente.

Pretendo contribuir não apenas para uma antropologia da história tal como proposta por Trouillot, mas também para a linha da antropologia da temporalidade inaugurada por Carol Greenhouse (1996). Usando exemplos da China antiga, do México pré-colonial e dos Estados Unidos contemporâneos, o estudo de Greenhouse sustenta que as diversas concepçóes culturais de tempo têm um aspecto inerentemente político e são indissociáveis de esforços de legitimação e contestação do poder político. Nas suas palavras, "as construçóes culturais do tempo servem de reservatórios de signos e símbolos de legitimidade política vindos de cima ou de baixo [da estratificação social]" (Idem, p. 110). O que analiso aqui é como, mesmo em uma situação de forte cinismo e disseminadas dúvidas em relação a um discurso oficial, as representações temporais desse discurso - nesse caso, baseadas na ideia de "Revolução" - podem obter um caráter hegemônico e contribuir assim para manter o poder político que promove tal discurso.

\section{Benjamin e Anderson}

Acredito que o estudo dos múltiplos sentidos da palavra "Revolução" em Cuba nos permite não apenas entender a historicidade que ela ajuda a produzir naquele país, como também discutir a temporalidade do nacionalismo em geral e questionar uma ideia amplamente aceita a respeito dessa temporalidade. Em Comunidades imaginadas, o livro que inaugurou os estudos contemporâneos do nacionalismo, Benedict Anderson postula que o nacionalismo é baseado em uma noção de tempo homogêneo e vazio. Os abundantes estudos do nacionalismo que se multiplicaram desde a publicação desse clássico têm se furtado a questionar essa ideia. Mais que isso, algumas análises mais recentes, como as de William Sewell (2004) e Manu Goswa- mi (2004), têm às vezes aplicado essa ideia à dimensão espacial, sustentando que o nacionalismo produz também um espaço homogêneo e vazio. Num movimento inverso aos desses autores, meu argumento é que a noção de "Revolução" que estrutura o nacionalismo cubano questiona a validade da concepção andersoniana da temporalidade do nacionalismo.

Benedict Anderson descreve o tempo homogêneo e vazio como "uma concepção da história como uma cadeia interminável de causa e efeito e de separaçóes radicais entre passado e presente" (Anderson, 1991, p. 23). A essa historicidade Anderson contrapóe um tempo messiânico, no qual há "uma simultaneidade de passado e futuro em um presente instantâneo” (Idem, p. 24), e no qual eventos anteriores prefiguram eventos posteriores que os cumprem e revivem. Anderson menciona como exemplo dessa outra noção de tempo - nem vazia nem homogênea - a simultaneidade que o cristianismo tradicional via entre o passado bíblico e o presente dos que o celebravam. Em contraposição, segundo o antropólogo britânico, o tempo do nacionalismo supóe uma cadeia causal e separa radicalmente o presente do passado.

Como se sabe, a oposição de Anderson entre um "tempo homogêneo e vazio" e um "tempo messiânico" foi retirada das teses Sobre o conceito de história, de Walter Benjamin, escritas em 1940. ${ }^{4}$ Mas há várias diferenças fundamentais entre os dois autores, das quais quero ressaltar duas. Primeiro, Benjamin não discute o nacionalismo explicitamente e, portanto, nâo o associa a nenhum dos dois tipos de temporalidade. Foi Anderson que aplicou tal oposição à crítica do nacionalismo. Segundo, para Benjamin o tempo messiânico não era apenas o das religiôes de salvação, mas também o tempo da revolução. A noção revolucionária de história, segundo Benjamin, carrega sempre a marca do presente, pois ela póe em cheque o suposto contínuo cronológico da história e estabelece uma conexão fundamental entre presente e passado. Ela dá, nas palavras de Benjamin, um "salto de tigre em direção ao passado" (Benjamin, 2007, p. 261) para reivindicar a redenção não apenas dos oprimidos de hoje, mas também dos oprimidos do passado. $\mathrm{O}$ famoso anjo da história de Benjamin olha para trás em grande 
parte porque o que ele chama de "ódio" e "vontade de sacrifício" dos revolucionários "se nutrem da visão dos ancestrais escravizados, e não do ideal dos descendentes libertados” (Idem, p. 260). Há várias interpretaçóes sobre o que exatamente Benjamin quis dizer por "tempo homogêneo e vazio", mas o que se pode dizer com certeza é que esse tempo, segundo ele, narra a história como um contínuo e cria uma distância entre presente e passado. Ele é o oposto da temporalidade revolucionária messiânica, que faz "explodir o contínuo da história" (Idem, p. 262) porque nela o presente se apropria ativamente do passado.

\section{Nacionalismo e temporalidade}

São notáveis as semelhanças entre a noção benjaminiana de tempo messiânico e a temporalidade subjacente ao conceito de "Revolução" do discurso cubano oficial. Ao ver na luta nacionalista do século XIX e, em menor medida, no conflito armado da década de 1950 a base principal da legitimidade do governo atual, esse discurso tem muito mais afinidades com a visão de história de Benjamin que com a teleologia progressista do marxismo clássico. É verdade que o discurso oficial cubano também contém noções de um futuro de fartura e liberdade, de um edênico comunismo por vir. Mas essa visão de futuro é subsumida hierarquicamente (no sentido de Dumont, 1966) pela preponderância abrumadora das narrativas sobre o passado. O que o discurso oficial sobre a "Revolução" enfatiza e glorifica não é o télos de um futuro mais ou menos distante, mas a presença contínua de um passado de lutas e injustiças, uma conexão íntima entre lutas e heróis do passado e lutas e heróis do presente. O olhar da "Revolução" cubana não é tão unidirecional como a do anjo da história de Benjamin que só se volta para trás -, mas ele só se volta para a frente de forma ocasional e secundária. Seu foco principal é o passado - que nunca é totalmente passado, pois está sempre presente.

Isso se faz notar na ideia central do discurso oficial - expresso em uma das anedotas que abriram este artigo - de que a "Revolução" cubana de hoje é a mesma "Revolução" que se iniciou em 1868. Essa mensagem é continuamente transmitida pela propaganda governamental massiva que ocupa o espaço público cubano - nos meios de comunicação, nas escolas, em murais e pôsteres, em rituais e monumentos. Bons exemplos são dois dos principais lemas do governo. O primeiro - "Nosotros como ellos, ellos como nosotros" - afirma que os governantes de hoje teriam feito no século XIX o mesmo que fizeram os revolucionários de então, e que os revolucionários do século XIX fariam hoje o mesmo que fazem os governantes atuais. Várias técnicas discursivas e visuais estabelecem essa conexão e compóem um verdadeiro monopólio da narrativa pública sobre o independentismo cubano, que só pode ser narrado publicamente como antecessor e legitimador da luta armada da década de 1950 e, por conseguinte, do governo cubano atual. Disso é testemunho o fato de que a mais grandiosa celebração histórica já realizada em Cuba aconteceu por ocasiáo do centenário do início da luta pela independência, que paralisou a ilha e movimentou um elevado número de pessoas e recursos em 1968.

A fixação do discurso oficial com as lutas anticoloniais do século XIX fica clara também no segundo lema do governo que quero destacar. Esse lema descreve o herói nacional José Martí como o autor intelectual del Moncada, ou seja, o autor intelectual do primeiro ato revolucionário da década de 1950 (muito embora Martí tenha morrido em 1895, durante a guerra de independência que ele ajudou a organizar). Essa expressão foi usada pela primeira vez por Fidel Castro em 1953, quando se defendeu do frustrado ataque que ele liderou contra o quartel Moncada, em Santiago de Cuba, e é hoje incessantemente repetida no discurso oficial e conhecida por qualquer cubano. A mesma mensagem é também repetidamente transmitida de maneira visual, pois uma das imagens mais reproduzidas da história da ilha é uma fotografia de Fidel Castro tirada em uma delegacia de polícia quando ele foi preso devido ao ataque ao quartel Moncada. Nessa imagem, um taciturno Fidel Castro aparece abaixo de um retrato de José Martí, como se estivesse sendo inspirado ou abençoado pelo líder independentista.

Essa foto faz parte do imenso aparato institucional que afirma dia e noite que não há ruptura entre revolucionários do passado e do presente. Muitas vezes, essa ligação é feita através de citações 
anacrônicas - como o uso em outdoors, cartazes e livros escolares de uma frase de José Martí que diz: "El Partido es el alma de la Revolución”. O partido a que Martí se referia era o Partido Revolucionario Cubano, a organização independentista que ele criou nos Estados Unidos, e por "Revolução" ele denotava a luta armada contra o colonialismo espanhol. No contexto atual de Cuba, contudo, essa frase é facilmente lida como se referindo ao Partido Comunista de Cuba (criado em 1965 e desde então o único existente no país) e a seu governo, chamado de "Revolução". Por meio dessa citação, o Partido de hoje dá um "salto de tigre" para o passado e se alimenta do Partido de Martí, criando no processo uma só "Revolução".

O salto do tigre revolucionário se concentra sobretudo no século XIX, mas também se volta para os anos da luta armada contra Fulgencio Batista, na década de 1950. Isso pode ser exemplificado pelo uso da citada imagem de Fidel Castro junto a um retrato de Martí em um cartaz que circulou amplamente em Cuba no cinquentenário da tomada do poder pelos revolucionários, entre 2008 e 2009. Nesse cartaz, um velho Fidel Castro aparece sorrindo vitorioso sob sua própria fotografia, descrita acima, junto a um retrato de Martí. Vale dizer, essa imagem mostra um velho Fidel Castro inspirado por um jovem Fidel Castro, que por sua vez é inspirado por Martí. Outro exemplo visual dessa dupla orientação ao passado é a gigantesca pintura mural instalada na rodoviária de Havana, no qual imagens dos revolucionários do século XIX aparecem ao lado de imagens dos revolucionários da década de 1950, unidas por uma imensa representaçáo do rosto de Martí.

A relação entre passado e presente que se vê nesses exemplos é, precisamente, aquela que Anderson descrevia como caracterizando o tempo messiânico, na qual momentos anteriores antecipam momentos posteriores, que representam sua culminação e vivificação. Por um lado, a luta independentista do século XIX prefigura a luta armada da década de 1950 e o governo atual; por outro, esse governo cumpre e revive tanto o conflito contra a Espanha quanto a luta armada da década de 1950. Esse duplo caráter da década de 1950 ajuda a entender sua ubiquidade no espaço público cubano. Os atos revolucionários daquela década são narrados e celebrados em inúmeras séries de televisão, filmes, livros de memórias, contos, romances, álbuns de figurinha, monumentos, placas, e até rituais públicos que os reproduzem performaticamente. Mas esses mesmos meios repetidamente descrevem o status quo cubano da década de 1950 como marcado pela corrupção, pela violência e pelo poder norte-americano. Esse retrato de uma ilha moralmente decadente - a Cuba das prostitutas, cassinos e hotéis de luxo - é um negativo tanto do heroísmo dos revolucionários da época como da ordem estabelecida por eles oficialmente descritos, ainda hoje, quando já são octogenários, como eternos jóvenes rebeldes.

O olhar nacionalista do anjo da história cubano, fixado no século XIX e na década de 1950 , gerou uma profusão de aniversários e efemérides, em que o passado e o presente são continuamente ligados. Uma das expressóes mais visíveis dessa profusão são as inúmeras efemérides elencadas diariamente em vários âmbitos - nos atos patrióticos que abrem cada escola cubana todas as manhãs, em programas de televisão, em colunas de jornais -, todos sempre contando o que representa este día en la historia. Tomando um exemplo, anualmente no dia 5 de maio o público cubano é chamado a comemorar três eventos: o nascimento de Karl Marx, em 1818; o encontro entre três líderes da independência cubana em uma fazenda do leste da ilha, em 1895; e o começo da primeira visita oficial de Fidel Castro ao Brasil, em 1959.5

Para além dessas referências diárias, os cidadãos de Cuba estão sempre sendo chamados a celebrar publicamente alguma data especial. Não me refiro apenas aos grandes atos comuns de comemoração de datas patrióticas - que trazem multidóes às ruas do país em dias como o $1^{\circ}$ de Maio e o 26 de Julho -, mas também aos inúmeros rituais públicos diários que celebram datas nacionais que não chegam a constituir feriados (a morte ou nascimento de algum herói nacional, por exemplo) ou algum grupo específico (dia da juventude, dia dos bombeiros, dia dos engenheiros etc.). A profusão de aniversários informa também o âmbito da criação artística, como exemplifica uma exposição que visitei em Havana que comemorava os vinte anos de uma ou- 
tra exposiçáo, que por sua vez comemorara os trinta anos do triunfo de la Revolución. De outra feita, em um imponente teatro da capital cubana, assisti à ária de uma ópera ser interrompida por uma voz em off que celebrava o aniversário de trinta anos de carreira do tenor que acabava de ser interrompido.

Heterogêneo e messiânico Se Benedict Anderson está certo em dizer que a imprensa cria uma noção de simultaneidade entre os habitantes de um território que lhes permite imaginar-se como membros de uma mesma comunidade, os vários meios de comunicação em Cuba convidam não apenas a uma simultaneidade entre os que são expostos a eles no presente, mas também a uma simultaneidade entre esse presente e um passado imaginado. Nada poderia estar mais distante do tempo homogêneo e vazio analisado por Anderson, que cria uma ruptura entre passado e presente. No discurso nacionalista cubano, o passado vive no presente, e o presente repete o passado. Portanto, a temporalidade nacionalista da "Revolução" se aproxima muito mais do tempo messiânico tal qual descrito por Benjamin e Anderson, em que passado e presente são simultâneos. Dada a importância fundamental de comemoraçôes para qualquer nacionalismo, não há razóes para supor que o caso cubano seja uma exceção. Muito pelo contrário, a profusão de aniversários do nacionalismo cubano é apenas uma versão exacerbada da relação de simultaneidade entre passado e futuro que pode ser vista em outros nacionalismos, todos eles pautados por datas patrióticas. Nacionalismos fundados na ideia de conexão com e na revivificação de um passado glorioso não faltam na bibliografia sobre o tema como mostram os estudos de Verdery (1991) sobre a Romênia, de Lomnitz (2001) sobre o México e de Abu El-Haj (2001) sobre Israel. ${ }^{6}$

Mais que isso, longe de ser homogênea e vazia, a temporalidade nacionalista é altamente heterogênea e cheia de significado. Embora o calendário ocidental afirme a igualdade e a neutralidade valorativa das unidades temporais de mesma categoria, a extensa bibliografia sobre aquilo que os historiadores costumam chamar de "memória coletiva" indica que em todo nacionalismo alguns anos e alguns dias são mais iguais que os outros. Em Cuba, anos fetichizados - como 1868, 1895, 1953, 1959 - não são imaginados da mesma maneira que anos como outros quaisquer, nem são imagináveis sem seu indissociável conteúdo nacionalista. De forma similar, vários dias marcados como nacionais estão repletos de conteúdo simbólico que os diferenciam dos demais. Por menos que se acredite ou concorde com o discurso oficial, não se pode experimentar o dia 28 de Outubro como o dia 27 ou 29, pois naquele milhares de pessoas saem de seus trabalhos, escolas e faculdades para lançar flores ao mar em memória do desaparecimento do comandante Camilo Cienfuegos. A celebração do 26 de Julho, data maior da "Revolução" - o aniversário do citado ataque ao quartel Moncada - chega a fetichizar o próprio número 26, o que é expresso no lema recorrente sobre a data - "Siempre es 26" - ou na repetida convocação anual que os cidadãos participem de un 26 por la patria.

Se o caso cubano sugere que Benedict Anderson está equivocado sobre a temporalidade nacionalista, ele parece confirmar a ligação que Walter Benjamin estabelece entre revolução e tempo messiânico. Como os exemplos que citei indicam, os comentários do pensador alemão sobre a Revolução Francesa poderiam se aplicar facilmente ao caso cubano. Se Benjamin descrevia a temporalidade da Revoluçáo Francesa como messiânica porque ela se via como "Roma retornada" (Benjamin, 2007, p. 261), os governantes de Cuba socialista constroem o mesmo tipo de temporalidade ao se apresentaram como a "Revolução" retornada. Ademais, nos diz Benjamin sobre o calendário revolucionário francês, um dia de fundação original "retorna sempre na figura dos dias de festa, que são dias de rememoração" (Idem, ibidem). Suas palavras são igualmente válidas para o calendário celebratório instituído pelo socialismo cubano e, mais que isso, para qualquer calendário de comemoraçóes nacionalistas. Nesse ponto, aliás, fica evidente o desacordo entre Benjamin e Anderson, já que este vê no calendário precisamente o oposto daquele: uma expressão e um meio do tempo homogêneo e vazio (Anderson, 1991, p. 24).

Há, porém, duas diferenças cruciais entre a revolução messiânica de Benjamin e a do discurso oficial cubano. Primeiramente, Benjamin atribui a sua revolução um caráter universal - trata-se de uma libertação de todos os oprimidos ou, mais am- 
plamente ainda, de toda a humanidade. Já no caso de Cuba, a "Revolução" é explícita e fundamentalmente nacionalista. A "Revolução" cubana foi - e em algumas partes ainda é - muitas vezes narrada como parte de um movimento libertador universal, mas ela é apresentada antes de tudo como a libertação nacional, como a base da soberania da comunidade imaginada. E, se pensarmos em outras revoluções de significação supostamente global, o caso cubano, mais uma vez, não parece ser a exceção, mas um exemplo da regra histórica.

Como demonstrou Reinhardt Koselleck (2004), a própria ideia moderna de revolução nasceu ao final do século XVIII e se desenvolveu durante o século XIX - ou seja, sua trajetória segue de perto a do nacionalismo. Mais que isso, o próprio trabalho de Anderson e o de Sewell (2004) mostram que não só as independências das colônias britânicas norte-americanas, mas o outro grande processo que propagou a própria noção de revolução - a Revolução Francesa -, tiveram um caráter eminentemente nacionalista. Até mesmo as revoluçóes socialistas do século XX, nas quais alguns gostariam de ver apenas um conflito e um discurso de classe, tiveram uma base fortemente nacionalista. Se isso é bastante claro para os socialismos pós-coloniais da África e da Ásia (Donham, 1999), análises da Revolução de 1917 (Fitzpatrick, 1999; Suny, 1993) mostram que também no Império Russo o socialismo atraía menos como promessa de redenção de classe que como uma maneira de vencer a dominação estrangeira e superar o suposto atraso nacional em relação ao Ocidente. Em suma, desde que se inventou o conceito de revolução, os processos históricos designados por esse termo têm sido claramente nacionalistas - o que dá razão à afirmação de Benedict Anderson de que o nacionalismo e a ideia de revolução são "concepçóes gêmeas" (Anderson, 1991, p. 156). Benjamin também estava correto ao enxergar nas revoluçóes um tempo messiânico, mas sua esperança de um messianismo universal tem sido frustrada pelo caráter nacionalista dos vários messianismos revolucionários. Sob esse aspecto, mais uma vez, Cuba aparece como exemplo da regra, e não como exceção.

\section{"Revoluçáo" e reveses}

Há uma diferença crucial entre a "Revolução" cubana e outros casos históricos normalmente chamados de revolução, como observei anteriormente. Ao contrário da cubana, as demais "revoluçóes" geralmente designam transformaçôes políticas, econômicas e sociais circunscritas temporalmente e de duração relativamente curta. Por mais que as Revoluçóes Americana, Francesa, Haitiana e Russa, por exemplo, tenham sido a base dos governos a que deram lugar, o termo "Revolução" não era, nem é, comumente usado para designar os governos de Jefferson, Napoleão, Dessalines ou Stalin. Em contraposição, ainda hoje este é o termo comumente utilizado para se referir ao governo dos irmáos Castro.

Esse fato aponta para a segunda diferença fundamental entre a revolução messiânica de Benjamin e a "Revolução" cubana. Para Benjamin - e não só para ele -, uma revolução só se pode entender como um processo subversivo contra um poder estabelecido, enquanto que em Cuba a noçáo de "Revolução" tem sido nos últimos 57 anos a base de um discurso de poder, dedicado à manutenção de um status quo e de uma distribuição desigual de recursos e baseada no silenciamento de qualquer oposição. ${ }^{7}$ Qualquer que seja nossa persuasão política, essa excepcionalidade da ideia de "Revolução" em Cuba nos faz perguntar como um governo que tem se mantido altamente estável por várias décadas ainda logra definir-se como "Revolução". Afinal, o que há para revolucionar depois de tanto tempo?

A meu ver, a resposta se encontra mais uma vez no discurso oficial. Desde a década de 1960, o Estado cubano tem repetidamente ressaltado seus reveses e declarado seu fracasso em atingir seus maiores objetivos. Isso se aplica a algumas das principais campanhas que ele travou ao longo de décadas, tais como a obtenção de safras recordes de cana de açúcar, a industrialização, a limitação do poder dos burocratas, e, muito especialmente, a devolução do território da Base Naval de Guantánamo e o fim do embargo norte-americano (Domínguez, 1978; Eckstein, 2003). Algumas dessas campanhas têm sido denominadas revoluções dentro da Revolução, como a "revolução técnica" da década de 1960, a "revolução da família” na década de 1980 e a atual 
"revolução energética". Não é à toa que um dos lemas favoritos do governo é "Trasformar reveses en victorias”. É claro que o discurso oficial também repetidamente proclama diversas vitórias do regime socialista - a erradicação do analfabetismo, a disseminação do ensino secundário, os positivos indicativos de saúde pública, o crescimento do turismo etc. - , mas tais proclamaçóes são tímidas em comparação à ininterrupta ênfase discursiva nos reveses, fracassos e problemas enfrentados pelo país. Mesmo a expressão usada para descrever a tomada de poder dos revolucionários em $1^{\circ}$ de janeiro de 1959 - el triunfo de la Revolución - simbólica e implicitamente reduz a apenas um os êxitos revolucionários dignos de serem celebrados.

Mais que isso, como algumas campanhas são de fato bem-sucedidas, a transformação de reveses em vitórias requer às vezes transformar vitórias em reveses, ou pelo menos dar visibilidade a novos e velhos reveses. Por isso, as batalhas vitoriosas são rapidamente substituídas por novas campanhas ou simplesmente esquecidas em prol da reafirmação da luta perene contra o imperialismo, simbolizado pela Base Naval de Guantánamo e pelo embargo estadunidense. Esse foi o caso, por exemplo, do retorno do pequeno náufrago Elián González a Cuba em junho de 2000, depois de um longo conflito judicial entre seu pai e sua família exilada em Miami (Bardach, 2002). O governo saía vitorioso de uma batalha simbólica de meses contra a liderança do exílio cubano, durante a qual realizara um esforço mediático sem precedentes e mobilizara a população em manifestaçôes multitudinárias pelas ruas do país. Mas o discurso que Fidel Castro realizou logo depois dessa vitória frisou que enquanto o imperialismo não fosse totalmente vencido a luta não cessaria, e isso estava longe de acontecer: "Transcorreram apenas umas horas desde o emotivo regresso de Juan Miguel e [seu filho] Elián a nossa pátria, convertidos em dois gigantes morais, e nossa luta, sem trégua nem descanso, se reinicia vigorosamente para entrar em uma nova e prolongada fase. Não somos um povo que se detém a saborear o prazer das vitórias nem a vangloriar-se de seus sucessos" (Castro, 2000). O público era convidado a recomeçar a luta após uma pequena pausa e a privilegiar não as vitórias, mas os reveses passados e presentes.
Ademais, logo depois do retorno de Elián González, o governo lançou uma nova campanha pública, doméstica e internacional, pela libertação de cinco cubanos presos por espionagem nos Estados Unidos. Os chamados cinco héroes estavam em cadeias norte-americanas havia mais de dois anos, mas apenas com o vácuo causado pelo retorno de Elián sua prisão foi tornada pública na ilha e convertida na base de uma nova "batalha". Essa campanha durou treze anos. A libertação e o retorno à ilha dos últimos desses cinco cubanos em fins de 2014 foi um dos efeitos mais imediatos da atual reaproximação entre os governos cubano e estadunidense. Essa reaproximação, aliás, veio acompanhada de nova ênfase do discurso oficial na luta contra o embargo e pela devolução do enclave norte-americano na província de Guantánamo. Raúl Castro tem advertido cuidadosa e reiteredamente aos cubanos que a vitória final ainda não está próxima e que tempos ainda mais difíceis se anunciam. Além disso, as reformas econômicas levadas a cabo recentemente em Cuba foram acompanhadas de um novo lema que as interpreta como a mais recente batalha do socialismo: La batalla económica constituye hoy, más que nunca, la tarea principal.

Mas o que essa insistência em reveses tem a ver com a ideia de "Revolução"? Ora, essa sucessão de "batalhas" tem gerado entre os cubanos uma temporalidade de reviravoltas incessantes e dado legitimidade à ideia de que o regime socialista não apenas surgiu de uma revolução, como ainda é a "Revolução". Como o próprio governo nunca proclamou sua vitória final, e nunca deixou de reconhecer suas graves limitaçóes, tanto os cubanos que o apoiam como aqueles que o criticam veem no período desde 1959 um longo processo histórico de um conflito eternamente renovado, de repetição de ciclos de lutas e de um futuro que nunca pode ser atingido. Para citar mais um lema revolucionário, a ideia de uma eterna luta é bem expressa pela frase que, por lei, deve concluir toda comunicação política oficial, oral ou escrita, em Cuba: “¡Venceremos!". Ao colocar a vitória eternamente no futuro, essa frase afirma implicitamente que sempre se estará lutando pela vitória e que ela não virá nunca. Nessa visão, a "Revolução" cubana não apenas ainda não concluiu o que começou no século XIX, 
como também parece não poder terminar nunca. A produção e reafirmação dos fracassos e reveses possibilita que o governo cubano continue a ser chamado de "Revolução". Afinal, é claro, uma revolução vitoriosa deixa de ser revolução.

Para unir essa discussão do cultivo discursivo de reveses e fracassos com minha reflexão anterior sobre aniversários e comemoraçóes, quero salientar a centralidade da celebraçáo do frustrado ataque ao quartel Moncada em 26 de julho de 1953, que constituiu a maior derrota sofrida pelos rebeldes que lutavam contra Fulgencio Batista. Ou seja, a maior data cívica nacional é precisamente o aniversário do primeiro e maior fracasso revolucionário! Em contraste, o dia do triunfo revolucionário de 1959 - $1^{\circ}$ de janeiro - é claramente relegado a um segundo plano, sendo uma data pouquíssimo celebrada e de reduzido valor nacionalista. Com a celebração anual do 26 de julho, o governo cubano simbolicamente relembra e celebra os limites de seu próprio sucesso e reafirma, ainda que indireta e implicitamente, a impossibilidade de sua vitória final afinal, siempre es 26. Estamos aqui bem longe dos desfiles soviéticos que celebravam a vitória da Grande Revolução Socialista de Outubro (Binns, 1979). Estamos mais distantes ainda da proclamação feita na década de 1980 pelo governo da República Democrática Alemá, segundo a qual os objetivos da construção do socialismo já tinham sido atingidos (Borneman, 1992). Creio não ser preciso salientar quão desastrosas foram essas declarações de vitórias em outros países socialistas.

\section{“Revolução” e poder}

Uma das diferenças cruciais entre o socialismo do Leste Europeu e da antiga União Soviética e o socialismo cubano é que este tem contado com a polissemia do termo "Revolução" e com a temporalidade ligada a ele. Seu efeito pode ser visto nas duas faces dessa temporalidade da "Revolução" que tenho discutido aqui: a fixação no século XIX e na década de 1950 , por um lado, e a produçáo e reproduçáo de reveses e batalhas, por outro. Se, como mostrou Greenhouse (1996), uma dimensão política é inerente a toda temporalidade e, como afirmou
Trouillot (1995), toda historicidade é constituída por um poder e ajuda a constituí-lo, examino agora de que modo cada faceta da noção de "Revolução" que discuti aqui contribui para a conformidade política em Cuba.

Começo pela forte presença das referências à década de 1950 na mídia e no espaço público cubanos. Esse peculiar "salto de tigre" normalizou essa década, aos olhos de muitos cubanos, como o padrão de avaliação comparativa da situação atual do país. E geralmente o saldo é, obviamente, positivo para o presente. É comum que, depois de verbalizar críticas ao governo, algumas pessoas tenham seus comentários qualificados pela lembrança - expressa por elas mesmas ou por seus interlocutores de que a "Revolução" é preferível à tenebrosa era de Batista. Uma vez, por exemplo, um de meus informantes lamentava a homofobia oficial que ainda prevalecia em Cuba, mas acrescentou que isso não depunha contra a "Revolução", porque, afinal, o país tinha sido igualmente homofóbico antes de 1959. A possibilidade de que isso poderia ou deveria ter mudado desde então simplesmente não the ocorreu. A conversão da década de 1950 no padrão de referência e comparaçáo pelo qual se avalia o presente ajuda assim a reproduzir a autoridade moral do governo de Cuba.

Um efeito político semelhante é produzido pelo outro "salto de tigre" para o passado - a forte associação entre o governo atual e a luta anticolonial oitocentista, ambos apresentados como uma só "Revolução". A incessante representação da luta independentista como antecessora e inspiradora do regime atual deu a este o monopólio do uso público da maior narrativa nacionalista do país. Ademais, a maioria dos críticos ao governo na ilha tem se furtado a elaborar interpretações alternativas da epopeia independentista. ${ }^{8}$ Isso se deve em boa medida ao controle estatal da produção e circulação culturais, inclusive dos recursos necessários a elas. Mas suspeito que tal reinterpretação também é evitada pelo temor da associação dessa epopeia com um discurso oficial que a maioria da população vê hoje como uma machacadera, ou "amassação", uma repetição massacrante do mesmo tema. Isso aumenta ainda mais a identificação do nacionalismo cubano com o socialismo real. 
Por fim, efeitos políticos semelhantes podem ser atribuídos à predileção do nacionalismo oficial por derrotas e reveses. Acima de tudo, como argumentei, essa técnica contribuiu, e continua a contribuir, para a visão tacitamente aceita por todos de que o governo atual ainda é, depois de décadas, um governo revolucionário. Como o regime tem logrado ser universalmente referido como a "Revoluçâo", criticá-lo equivale a questionar o próprio valor da palavra-chave fetichizada que tem estruturado o nacionalismo cubano desde o seu surgimento no século XIX. Embora o termo "comunista" no discurso coloquial contemporâneo em Cuba geralmente tenha conotaçóes negativas - associadas a autoritarismo, oportunismo, e tendência à delação -, não se pode dizer isso da palavra "revolucionário", que continua tendo um valor moral positivo mesmo para os críticos do governo. Poucas pessoas na ilha teriam orgulho de serem chamadas de "contrarrevolucionárias", porque esse adjetivo tem até hoje uma inextricável relação com a ideia de traição à nacionalidade.

Além disso, a ênfase do discurso oficial nas dificuldades encontradas pelo socialismo e em batalhas eternamente renovadas tem uma estranha ressonância com a visão que os cubanos têm de sua própria vida cotidiana, desde pelo menos a severa crise econômica da década de 1990. Essa visão pode ser resumida por uma das expressóes mais típicas da linguagem popular cotidiana cubana atual: "No es fácil'. Uma espécie de mantra usado repetidamente pelos cubanos para comentar sobre as mais variadas dificuldades que encontram no dia a dia, essa frase é descrita pelo escritor Abilio Estévez como "um delicado eufemismo usado em qualquer circunstância adversa, e para os havaneses toda circunstância é adversa" (Estévez, 2004, pp. 248-249). Acompanhada amiúde de um suspiro, a expressão "No es fácil' é usada nas mais variadas situaçóes: quando um ônibus demora a chegar, quando se pisa em uma poça d'água, quando se perde um trabalho, quando não se encontram goiabas na feira, quando falta água, quando falta luz, quando não se encontra um médico na clínica do bairro.

Ora, um dos aspectos mais notáveis dessa expressão - no mais das vezes entendida como uma crítica pouco velada ao governo - é que ela pode resumir também o próprio discurso do governo.
Quando a voz nacionalista oficial reafirma as dificuldades do socialismo, proclama uma nova batalha diante de cada vitória, renova a luta eterna contra o imperialismo, e até quando celebra o fracasso do ataque ao quartel Moncada, o que ela diz no fundo é: "No es fácil". Tanto discursos oficiais quanto discursos populares em Cuba veem a experiência temporal da "Revoluçáo" como uma eterna repetição de lutas e batalhas, mesmo se uns usam essa temporalidade para criticar o governo e outros para apoiá-lo. A temporalidade das lutas cotidianas e a temporalidade das lutas lançadas pelo governo se espelham uma à outra, e ambas são uma sequência interminável de voltas à batalha. De fato, uma outra expressão muito corrente em Cuba aponta para essa coincidência: a palavra "lucha". Várias etnografias apontam para a irônica dualidade desse termo em Cuba (Allen, 2011; Weinreb, 2009), confirmada também por minha pesquisa etnográfica. No discurso oficial, lucha designa o combate contra o inimigo imperialista e contra vários obstáculos internos, enquanto no registro coloquial a mesma expressão é usada para descrever a experiência cotidiana em Cuba. Isso é expresso tanto explicitamente - "Vivir en este pais es una lucha" quanto implicitamente: quando se faz a alguém a pergunta cotidiana “¿Cómo estás?", uma das respostas mais corriqueiras que se obtém é "Ya tú sabes, en la lucha".

\section{Disco e furacáo}

Assim como os revolucionários de hoje repetem os do passado, as lutas de hoje não cessam de se repetir em Cuba. A "Revolução" cubana é marcada, como representação e como experiência, por um eterno retorno à luta, voltas incessantes a lutas anteriores - às do século XIX, às da década de 1950, às de uma ou duas décadas atrás, às do mês passado, às de ontem. Por essa razão a entendo como uma revolução rotatória, uma revolução baseada não em uma teleologia, mas em voltas e repetiçóes. A imagem da revolução rotatória me foi inspirada por dois comentários que ouvi em ocasióes diferentes, que criticavam a "Revolução" através de imagens giratórias. Uma vez, um camelô de seus trinta e poucos 
anos me disse que o Estado cubano havia criado algo muito original, um disco repetitivo de uma só rotação por minuto - ou, mais apropriadamente, "de una sola revolución por minuto". O segundo comentário eu ouvi quando estava em uma fila para comprar mantimentos na véspera da chegada anunciada de um furacão. Como apenas dez dias antes Havana tinha sido castigada por um outro furacão, alguém na fila divagou em voz alta se o novo furacáo seria mais devastador que o anterior. A isso uma senhora respondeu: "Mi vida, jnada puede ser peor que el huracán en que vivimos hace cincuenta años!".

As imagens do disco e do furacão possibilitam críticas muito perspicazes, e em seu conjunto refletem as duas formas de temporalidade que conectei ao termo "Revolução" - uma ligada a representaçóes históricas, a outra à experiência cotidiana. $\mathrm{O}$ comentário do camelô criticava o discurso oficial, ou seja, as representaçóes históricas incessantemente repetidas em vários meios de comunicação, que insistem em voltas a batalhas passadas. $\mathrm{O}$ comentário da senhora da fila ironizava as dificuldades da luta da vida cotidiana em Cuba, a volta constante a novas batalhas mundanas. Ambos comentários, porém, descrevem a "Revolução" com imagens circulares, e não como uma ruptura ou mudança. Disco ou furacão, a "Revolução" continua dando voltas.

Esses comentários indicam que estamos diante de uma noção de "revolução" que amalgama os dois sentidos do termo analisados por Reinhart Koselleck (2004): o sentido originalmente astronômico de um movimento giratório (uma volta) e o sentido político-histórico de uma transformação social (uma reviravolta). A temporalidade nacionalista da "Revolução" está longe, portanto, de ser linear. Se o calendário ocidental combina ruptura e repetiçáo (o que permitiu, aliás, que Benjamin e Anderson o associassem a temporalidades diferentes e mesmo opostas), a temporalidade da Revolução - com sua profusão de voltas, em vários aspectos, a momentos anteriores - dá preeminência à repetição, que dessa forma engloba hierarquicamente a duração. Talvez essa revolução rotatória seja peculiar a Cuba, mas espero ter mostrado que sua temporalidade apenas exagera e torna mais visível algo que subjaz a todo nacionalismo: um tempo heterogêneo e cheio de significados e de retornos.

\section{Notas}

1 A não ser nos casos em que indico o contrário, são minhas todas as traduçóes de falas de informantes e de textos citados. Este artigo é baseado em vários períodos de pesquisa de campo e de arquivo em Cuba, em um total de vinte e dois meses distribuídos entre 2000 e 2016, complementados por pesquisa de campo e de arquivo em Miami, realizada ao longo de dezoito meses distribuídos entre 2003 e 2011. Resumidamente, a pesquisa de campo em Cuba, localizada principalmente mas não exclusivamente em Havana, consistiu em observação participante de inúmeras atividades cotidianas e rituais, públicas e privadas, em diversos ambientes e locais, bem como em incontáveis conversas informais e oitenta entrevistas semiestruturadas com cubanos das mais diversas características sociais (ocupaçâo, idade, cor, local de moradia, procedência geográfica etc.). Agradeço ao Social Sciences Research Council por uma generosa International Dissertation Resarch Fellowship que me permitiu realizar doze meses contínuos de pesquisa em Cuba, entre 2008 e 2009. Agradeço também a outras instituiçôes que financiaram visitas de campo mais curtas: o Program in Latin American Studies, o Departamento de História e o Institute for Global Studies da Johns Hopkins University; o Explorers' Club, Washington Group; o Departamento de Antropologia e o Center for Latin American Studies da Universidade de Chicago. Também expresso minha gratidão pelo financiamento a pesquisas de arquivo que realizei fora de Cuba e que complementaram minha pesquisa sobre a ilha: uma Residential Fellowship no Instituto Iberoamericano de Berlim, em 2009; e uma Graduate Research Fellowship da Cuban Heritage Collection da Universidade de Miami, em 2011.

2 Nenhum dos trabalhos citados nesse parágrafo discute explicitamente os significados ou o uso político da ideia de "Revoluçâo". Até onde sei ainda não há uma história crítica desse conceito em Cuba. Porém, as análises desses autores e as diversas fontes que citam atestam o uso fetichizado do termo "Revoluçáa", que observo aqui.

3 Devo observar que, se eu fosse convidado a me posicionar sobre quando aconteceu uma revoluçáo em Cuba, eu afirmaria, seguindo analistas como Marifeli Pérez-Stable (1993), que ela aconteceu entre 1959 e 1961, quando Cuba transitou do capitalismo ao socialismo real, e se aprofundou entre 1968 e 1970, com a chamada Ofensiva Revolucionaria, que aboliu as pequenas empresas capitalistas que ainda permaneciam no país. 
4 A minha discussão do texto de Walter Benjamin é baseada sobretudo em sua tradução ao inglês feita por Hannah Arendt (Benjamin, 2007). Porém, cito neste artigo o título e passagens do texto de Benjamin tal como aparecem traduzidos na edição brasileira do livro de Michael Löwy (2005). Minha interpretação do clássico de Benjamin é também bastante informada pelo ensaio de Löwy.

5 Obtive a informaçáo sobre as efemérides dessa data (que de outra forma não tem qualquer relevância nacional) do portal estatal Cuba.cu (disponível em efemerides.cuba.cu/index. php?sid=9b4b4fc987d6517b 1405bcfdff909aaf, consultado em 5/5/2015).

6 Isso fica claro na própria análise empírica de Benedict Anderson, especialmente no prefácio e nos capítulos que adicionou à segunda edição revista de Comunidades Imaginadas (1991). O capítulo "Memória e esquecimento", por exemplo, enfatiza que vários nacionalismos em todo o mundo se baseiam na ideia do despertar moderno e messiânico de uma antiga nação que se mantivera adormecida por séculos. Esse tipo recorrente de narrativa, é claro, póe em dúvida a ideia de uma temporalidade nacionalista baseada na separação entre passado e presente, mas essa contradição náo levou Anderson a rever seu argumento de que o nacionalismo depende de um tempo homogêneo e vazio. Ou seja, o próprio Anderson fornece bases empíricas para a crítica de seu argumento teórico - que, contudo, continua sendo reafirmado pelos estudos contemporâneos do nacionalismo.

7 Faço essas observaçôes, a meu ver factuais, como antropólogo. Elas não devem ser entendidas, portanto, como uma crítica política de oposição. Creio que o governo cubano, como qualquer outro, está aberto à análise social - crítica no sentido mais amplo do termo - que não deve dar lugar a romantizações políticas. A literatura acadêmica está repleta de análises das desigualdades e silenciamentos promovidas em Cuba durante as últimas décadas (ver, por exemplo, de la Fuente 2001, Eckstein, 2003; Espina e Rodríguez, 2006; Guerra, 2012; Rodríguez e Estévez, 2006; Weinreb 2009).

8 Isso tem sido diferente de Miami, onde desde 1959 exilados das mais diversas tendências políticas têm se dedicado a reinterpretar essa epopeia independentista de um ponto de vista oposicionista, segundo o qual os líderes do exílio são os verdadeiros herdeiros e continuadores da luta anticolonial do século XIX. Ver Gonçalves, 2015.

\section{BIBLIOGRAFIA}

ABU EL-HAJ, Nadia. (2001), Facts on the ground: archeological practice and territorial self-fashioning in Israeli society. Chicago, University of Chicago Press.

ALLEN, Jafari. (2011), ¡Venceremos? The erotics of black self-making in Cuba. Durham, NC, Duke University Press.

ANDERSON, Benedict. (1991), Imagined communities: reflections on the origin and spread of nationalism. 2. ed. rev. Londres, Verso.

BARDACH, Ann Louise. (2002), Cuba confidential: love and vengeance in Miami and Havana. Nova York, Random House.

BARCIA, María del Carmen. (2005), Capas populares y modernidad en Cuba (1878-1930). Havana, Fundación Fernando Ortiz.

BENJAMIN, Walter. (2007), "Theses on the Philosophy of History”, in __ Illuminations: essays and reflections. Org. e trad. Hannah Arendt, Nova York, Schoken.

BINNS, Christopher A. P. (1979), “The changing face of power: revolution and accommodation in the development of the Soviet ceremonial system: Part I”. Man, 14 (4): 585-606.

BORNEMAN, John. (1992), Belonging in the two Berlins: kin, State, nation. Cambridge, Cambridge University Press.

BOURDIEU, Pierre. (1991), Language and symbolic power. Cambridge, Harvard University Press.

CASTRO, Fidel. (2000), "Mensaje de Fidel a la tribuna abierta de Manzanillo". Disponível em www.cuba.cu/gobierno/discursos/2000/esp/ f010700e.html, consultado em 05/05/2015.

COMAROFF, Jean \& Comaroff, John. (1991), of revelation and revolution, vol. 1 . Chicago, University of Chicago Press.

CUNHA, Manuela Carneiro da. (2009), “ 'Cultura’ e cultura: conhecimentos tradicionais e direitos intelectuais", in Cultura com aspas e outros ensaios, São Paulo, Cosac Naify.

DE LA FUENTE, Alejandro. (2001), A Nation for All: Race, Inequality, and Politics in Twentieth-Century Cuba. Chapel Hill: University of North Carolina Press. 
DOMÍNGUEZ, Jorge. (1978), Cuba: order and revolution. Cambridge, Harvard University Press.

DONHAM, Donald. (1999), Marxist modern: an ethnographic history of the Ethiopian Revolution. Berkeley, CA, University of California Press.

DUMONT, Louis. (1966), Homo hierarchicus: le système des castes et ses implications. Paris, Gallimard.

ECKSTEIN, Susan. (2003), Back from the future: Cuba under Castro. Londres, Routledge.

ESPINA PRIETO, Rodrigo \& RODRÍGUEZ RUIZ, Pablo. (2006), "Raza y desigualdad en la Cuba actual". Temas: Cultura, Ideología, Sociedad, 45: 44-54.

ESTÉVEZ, Abilio. (2004), Inventario secreto de La Habana. Barcelona, Tusquets Editores.

FERRER, Ada. (1999), Insurgent Cuba: race, nation, and revolution, 1868-1898. Chapel Hill, NC, University of North Carolina Press.

FITZPATRICK, Sheila. (1999), Everyday stalinism: ordinary life in extraordinary times. Oxford, Oxford University Press.

GARCÍA, María Cristina. (1996), Havana, USA: Cuban exiles and Cuban Americans in South Florida, 1959-1994. Berkeley, CA, University of California Press.

GONÇALVES, João Felipe. (2013), "Sputnik premiers in Havana, a historical ethnography of the 1960 Soviet exposition", in A. Gorsuch e D. Koenker (orgs.), The socialist sixties: crossing borders in the second world, Bloomington, IN, University of Indiana Press.

. (2015), "Martí versus Martí: nacionalismo e hegemonia em Havana e Miami”. Novos Estudos Cebrap, 102: 73-91.

GOSWAMI, Manu. (2004), Producing India: from colonial economy to national space. Chicago, University of Chicago Press.

GREENHOUSE, Carol. (1996), A moment's notice: time politics across cultures. Ithaca, NY, Cornell University Press.

GUERRA, Lilian. (2012), Visions of power: revolution, redemption, and resistance, 1959-1971. Chapel Hill, NC, University of North Carolina Press.

HELG, Aline. (1995), Our rightful share: the Afro-Cuban struggle for equality, 1886-1912. Chapel
Hill, NC, University of North Carolina Press.

IGLESIAS UTSET, Marial. (2003), Las metáforas del cambio en la vida cotidiana: Cuba, 18981902. Havana, Unión.

KOSELLECK, Reinhardt. (2004), Futures past: on the semantics of historical time. Nova York, Columbia University Press.

LOMNITZ, Claudio. (2001), Deep Mexico, silent Mexico: an anthropology of nationalism. Minneapolis, University of Minnesota Press.

LÖWY, Michael. (2005), Walter Benjamin: aviso de incêndio: uma leitura das teses Sobre o conceito de história. São Paulo, Boitempo.

PÉREZ JR., Louis. (1983), Cuba between empires, 1878-1902. Pittsburgh, PA, Pittsburgh University Press.

. (2006), Cuba: between reform and revolution. 3. ed. Nova York, Oxford University Press.

PÉREZ-STABLE, Marifeli. (1993), The Cuban Revolution: origins, course, and legacy. Oxford, Oxford University Press.

RODRÍGUEZ RUIZ, Pablo \& ESTÉVEZ MEZQUÍA, Claudio. (2006), "Familia, uniones matrimoniales y sexualidad en la pobreza y la marginalidad: el llega y pón, un estudio de caso”. Catauro - Revista Cubana de Antropologia, 8 (14): 5-31.

SEWELL JR., William H. (2004), "The French Revolution and the emergence of the nation form”, in M. A. Morrison e M. Zook (orgs.), Revolutionary currents: nation building in the transatlantic world, Lanham, MD, Rowman and Littlefield.

SUNY, Ronald Grigor. (1999), The revenge of the past: nationalism, revolution, and the collapse of the Soviet Union. Stanford, Stanford University Press.

THOMAS, Hugh. (1998), Cuba, or, The pursuit of freedom. Nova York, Da Capo.

TROUILLOT, Michel-Rolph. (1995), Silencing the past: power and the production of history. Boston, Beacon.

VERDERY, Katherine. (1991), National ideology under socialism: identity and cultural politics in Ceausescu's Romania. Berkeley, CA, University of California Press.

WEINREB, Amelia Rosenberg. (2009), Cuba in the shadow of change: daily life in the twilight of 
the revolution. Gainesville, FL, University Press of Florida.

ZANETTI LECUONA, Oscar. (2006), La República: notas sobre economía y sociedad. Havana, Ciencias Sociales. 


\section{REVOLUÇÁO, VOLTAS E REVESES: TEMPORALIDADE E PODER EM CUBA}

\section{João Felipe Gonçalves}

Palavras-chaves: Nacionalismo; Revolução; Temporalidade; Cuba; Walter Benjamin.

Este artigo discute a polissemia e o valor político do termo "revolução" como categoria da prática em Cuba e analisa a temporalidade e a historicidade que esse termo - ubíquo e fetichizado nesse país pressupooe e ajuda a produzir. Sustentando que a temporalidade da "revolução" em Cuba é marcada mais pela repetiçáo que por uma teleologia, o artigo desenvolve dois argumentos inter-relacionados. Primeiro, o uso dessa palavra-chave tem contribuído para a conformidade política e para a manutençáo do socialismo em Cuba; segundo, a historicidade subjacente ao uso generalizado do termo "revoluçâo” em Cuba estabelece uma relação íntima entre passado e presente e produz uma temporalidade altamente heterogênea e repleta de conteúdo simbólico. Esta noção de temporalidade póe em questão a ideia predominante nos estudos contemporâneos do nacionalismo, nos quais este conceito está ligado a um tempo homogêneo e vazio.

\section{REVOLUTION, RETURNS, AND SETBACKS: TEMPORALITY AND POWER IN CUBA}

João Felipe Gonçalves

Keywords: Nationalism; Revolution; Temporality; Cuba; Walter Benjamin.

This article discusses the polysemy and the political value of the term "Revolution" as a category of practice in Cuba, and analyzes the temporality and historicity that this term - ubiquitous and fetishized in this country - presupposes and helps to produce. Pointing out that the temporality of the "Revolution" in Cuba has a repetitive rather than a teleological character, the text makes two interrelated arguments. First, the use of this keyword has contributed to the political conformity and to the maintenance of socialism in Cuba. Second, the historicity underlying the generalized use of the term "Revolution" in Cuba establishes a close relationship between past and present, and produces a temporality that is highly heterogeneous and full of symbolic content. This notion of temporality challenges the prevailing scholarly view that nationalism is associated with an empty and homogeneous time.

\section{RÉVOLUTION, TOURNANTS ET REVERS : TEMPORALITÉ ET POUVOIR À CUBA}

\author{
João Felipe Gonçalves
}

Mots clés: Nationalisme; Révolution; Temporalité; Cuba; Walter Benjamin.

Cet article discute la polysémie et la valeur politique de l'expression «révolution» en tant que catégorie de la pratique à Cuba et analyse la temporalité et l'historicité que ce terme - omniprésente et fétichisé dans ce pays - présuppose et contribue à produire. Tout en défendant que la temporalité de la «révolution» à Cuba est davantage marquée par la répétition que par une téléologie, l'article développe deux arguments interreliés. Tout d'abord, l'utilisation de ce mot-clé a contribué à la conformité politique et à l'entretien du socialisme à Cuba; deuxièmement, l'historicité sous-jacente à l'emploi très répandu du terme «révolution» à Cuba établit une relation étroite entre le passé et le présent et produit une temporalité hautement hétérogène et chargée de contenu symbolique, qui remet en question l'idée répandue dans les études contemporaines du nationalisme selon laquelle cela est lié à un temps homogène et vide. 